F. Reprod. Fert. (1973) 33, 61-68

\title{
THE INDUCTION OF OVULATION AND OESTRUS IN THE CHINCHILLA
}

\author{
BARBARA J. WEIR \\ Wellcome Institute of Comparative Physiology, \\ Zoological Society of London, Regent's Park, London NW1 $4 R$ r
}

(Received 28th February 1972)

\begin{abstract}
Summary. Further investigations were made in the chinchilla, Chinchilla laniger, on the induction of ovulation and oestrus. Ghinchilla treated with exogenous gonadotrophins (PMSG and HCG) in various regimens came into oestrus $(73 \%$ ) and a mean number of 2.6 ova were ovulated per animal. Mating occurred in $18 \%$ and conception in $12 \%$ of the treated chinchilla. This response was considered promising for encouraging chinchilla to breed at all times of the year.
\end{abstract}

\section{INTRODUCTION}

Weir (1969) reported that ovulation could be induced in the chinchilla, Chinchilla laniger, with exogenous gonadotrophins but the responses obtained were not altogether satisfactory because of the low rate of coincidence of oestrus in those animals that ovulate $(87.5 \%)$. The recovery rate of eggs in flushings or in histological sections of the Fallopian tubes and uteri was low in comparison with the number of corpora lutea in ovarian sections. However, estimates of mean numbers of eggs ovulated (3.7) made by the latter method exceeded mean litter-size at birth resulting from natural ovulation and mating. It was concluded that overstimulation of the ovaries had occurred.

This fact prompted the investigation of lower doses of the same gonadotrophins and other means of inducing oestrus and ovulation that is reported in this paper. The willingness of the experimental animals to mate, and their ability to conceive and maintain a pregnancy following natural or artificial insemination was also tested as a step towards the formulation of a practical method for the treatment of infertility in the stocks of chinchilla held by commercial breeders.

\section{Animals}

\section{MATERIALS AND METHODS}

The 133 adult chinchilla used on twenty-seven occasions between March 1968 and December 1971 were taken from the laboratory breeding colony (Weir, 1967a) or donated by commercial breeders. Because of the scarcity of chinchilla for experimental purposes and the impossibility of using animals at identical stages of growth, reproductive cycle and season, the experiments were conducted during all months of the year irrespective of the November to May 
breeding season and the reproductive history of the animal. Selection for test was based on the interval since the last perforation of the vaginal membrane and for the majority of animals this period was greater than the mean length of one oestrous cycle which was 41 days (Weir, 1970).

The animals were checked daily for vaginal perforation, which is a reliable indication of oestrus in hystricomorph rodents (Weir, 1967b). Males were allowed access (Weir, 1967a) to most of the experimental females and when vaginal opening occurred, smears were taken and examined under phasecontrast microscopy for spermatozoa, and the litter trays were searched for copulatory plugs. Eighteen of the test females were inseminated artificially as part of another series of investigations.

\section{Treatments}

Sex hormones. Some preliminary experiments were performed with $0.1 \mathrm{mg}$ oestradiol benzoate and $0.5 \mathrm{mg}$ progesterone ( 80 to $84 \mathrm{hr}$ apart) alone and in conjunction with gonadotrophins (regimens II and IV of Weir, 1969). Although the sex hormones caused vaginal opening, the ovulatory response was poor. When the gonadotrophins were also used to induce ovulation, the separate effects of the two treatments were diminished and so this line of attack was abandoned.

Gonadotrophins. The gonadotrophins used were PMSG (Gestyl and Folligon, Organon) and HCG (Pregnyl and Chorulon, Organon). They were reconstituted in $0.85 \% \mathrm{NaCl}$ solution to a concentration of 50 i.u. $/ \mathrm{ml}$ and $100 \mathrm{i} . \mathrm{u} . / \mathrm{ml}$, respectively, and injected intraperitoneally at 10.00 hours. The main variants tested were (a) the duration of PMSG treatment, (b) a split or single dose of PMSG, and (c) the dose of HCG. Details of the various regimens used (A to J) are given in Table 1 .

Since not every animal was killed immediately after an experiment, some chinchilla that did not respond were treated more than once, the interval between treatments being at least 2 months. In all, ninety-seven animals were treated once, thirty received two courses, and six had three courses. After three separate courses of PMSG and HCG, there was no evidence of refractoriness to stimulation and three of the six animals so treated became pregnant after the last treatment. Therefore, the results for all the animals were combined (see Table 1).

Controls. Five animals were used as controls (injected with saline) in addition to those of Weir (1969).

Regimens II and IV of the previous experiments (Weir, 1969) were repeated mid-way through the present set of experiments as controls to test for variations in animals, different batches of hormones or technique.

The gonadotrophins, PMSG and HCG, were given separately to four and twelve chinchilla, respectively, to confirm and extend the contention (Weir, 1969) that both gonadotrophins were necessary to induce ovulation regularly in this species.

\section{Autopsy}

Detailed study of the chinchilla ovary (Weir, 1967b) has shown that it is 
rarely possible to determine the number of corpora lutea of ovulation by external examination of the ovaries, and therefore both ovaries of all the experimental animals killed were fixed in Bouin's fluid, and were then processed conventionally. Serial $5-\mu \mathrm{m}$ sections were cut, stained in Mayer's haemalum and eosin, and examined in detail.

The Fallopian tubes of chinchilla killed a few days after treatment were similarly treated or flushed with saline to recover the eggs. Uterine swellings were sectioned to establish the presence of fetal material when necessary.

It was not practicable to confirm ovulation in all treated chinchilla by the direct method indicated above, since one of the aims of these experiments was to follow the course of any resulting pregnancies. Therefore, although information on vaginal perforation was available for every animal, detection of svulation was possible only in chinchilla that became pregnant or were killed within a period during which corpora lutea could be identified with the treatment given. Fifty-five of the 121 animals indicated in Table 1 were killed within 28 days of the start of the experiment, and four were killed between 36 and 70 days. It was not possible to determine the ovulation rate accurately in two chinchilla which were killed in late pregnancy or in four which went to term because the ovary contains accessory corpora lutea as well as corpora lutea of ovulation in late pregnancy (Weir, 1966) and resorption is a common phenomenon in this species (Weir, 1967b).

\section{Gonadotrophin treatments}

\section{RESULTS}

The results of the regimens $A$ to $J$ are summarized in Table 1. Some of the groups were small and none contained animals of strictly equivalent status and since no clear-cut differences emerged in the responses to the various treatments, the choice of regimen to examine in greater detail $(\mathrm{J})$ was subjective. However, the results indicate that all these gonadotrophin regimens were more successful in inducing oestrus in chinchilla than were those reported by Weir in 1969. The analysis given in Text-fig. 1 shows that a proportion of the chinchilla responded with vaginal oestrus to PMSG only, that is before the HCG was administered. All the chinchilla that mated did so on the day that vaginal opening occurred, and two mated on the following night also. Since ovulation has been shown to occur about $18 \mathrm{hr}$ after HCG injection (Weir, 1969), the optimal time for vaginal and behavioural oestrus would appear to be on the day of HCG injection or within the next $24 \mathrm{hr}$. This condition is most closely approximated in the 6 -day treated animals (regimens $\mathrm{F}$ to $\mathrm{J}$ ) in which the mean time of vaginal opening was 6.9 days after the first PMSG injection. The intervals were 5.4 days in the 4-day (regimens $A$ to D) and 6.4 days in the 5-day (regimen E) treated animals. There were no differences in responses between the 4- and 6-day treatments (regimens $\mathrm{A}+\mathrm{B}+\mathrm{C}$ versus $\mathrm{H}+\mathrm{I}+\mathrm{J}$ ) with respect to numbers of animals showing vaginal opening $(87 \%$ versus $72 \%)$, ovulation $(44 \%$ versus $45 \%$ ), mating (both $18 \%$ ) and pregnancy (both $14 \%$ ). However, the mean ovulation rate per animal was higher $(3 \cdot 6 \pm 0 \cdot 8)$ in the 4-day group $(n=8)$ than that $(2 \cdot 6 \pm 0 \cdot 1)$ in the 6 -day group $(n=28)$. The difference between the means $( \pm$ S.E. $)$ is not significant but the range of eggs ovulated in the former 


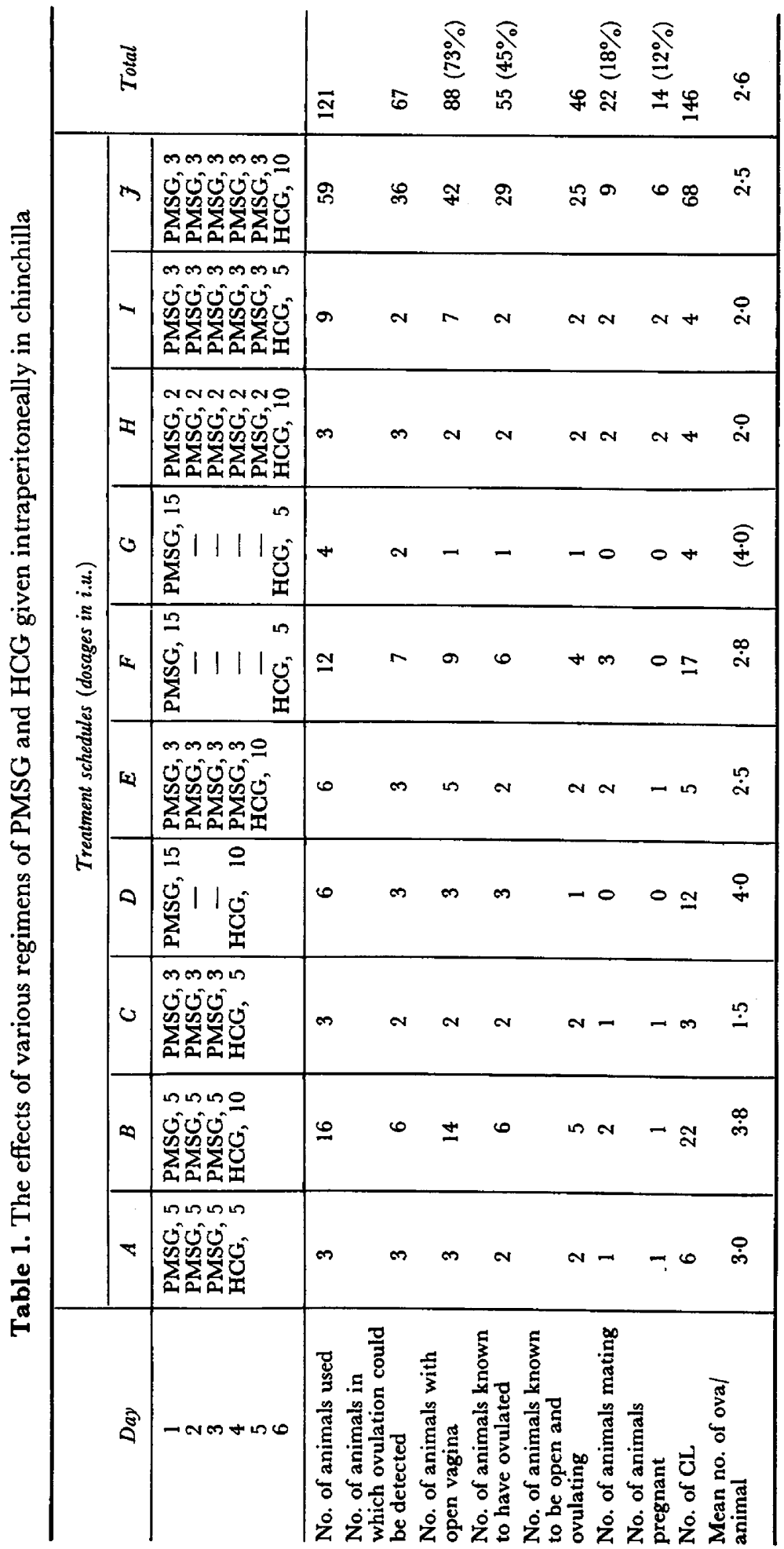




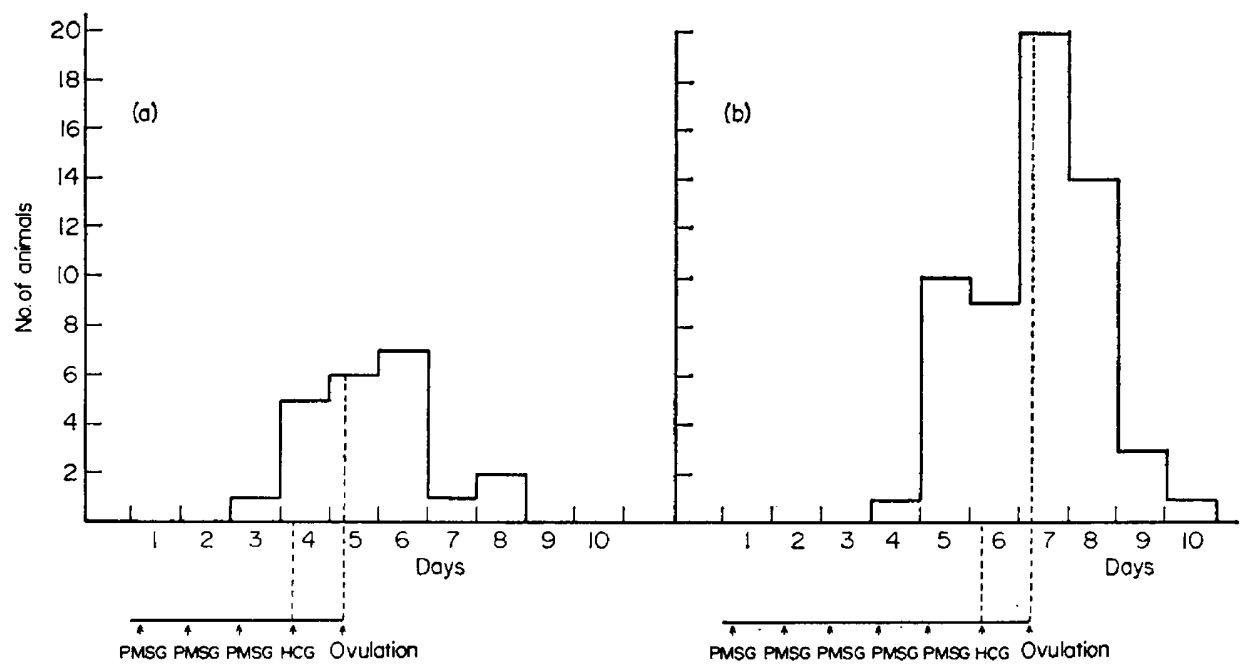

TExT-FIG. 1. Histograms showing the first day of vaginal perforation in chinchilla on (a) 4-day regimens (A to $D$ ) and (b) 6-day regimens ( $F$ to $\mathrm{J}$ ).

group (one to eight) was twice that in the latter in which the modal number was three. The incidence of mating and conception might have been greater in the 6-day group had not eighteen chinchilla been isolated for artificial insemination.

Although six of the twelve chinchilla treated with a single dose of PMSG (regimens $\mathrm{D}+\mathrm{F}+\mathrm{G}$ ) ovulated and came into oestrus (Table 1 ), only three mated (regimen F) and none became pregnant. Slightly more chinchilla $(84 \%$ versus $77 \%)$ ovulated when treated with 10 i.u. HCG (regimens $B+D+$ $\mathrm{F}+\mathrm{H}+\mathrm{J}$ ) than with 5 i.u. $\mathrm{HCG}$ (regimens $\mathrm{A}+\mathrm{G}+\mathrm{G}+\mathrm{I}$ ).

\section{Controls}

Only one of the controls injected with saline exhibited vaginal opening and ovulation.

The results from the seven chinchilla tested with gonadotrophin regimens II and IV of Weir (1969) corroborated the earlier ones in that ovulation was more readily induced than oestrus by these regimens. The mean ovulation rate of six eggs per animal was high and egg recovery was poor. The ovaries appeared overstimulated upon histological examination because luteinization of unovulated follicles and sometimes of theca interna and interstitial tissue had occurred.

PMSG alone. In addition to the two chinchilla described by Weir (1969), another two were treated solely with 5 i.u. PMSG on 3 consecutive days: neither vaginal opening nor ovulation was found. Another two chinchilla, treated with five daily doses of 3 i.u. PMSG, showed a perforate vagina on Day 5 and both mated. At autopsy, the ovaries of both contained new corpora lutea and blastocysts were found in the uterus of one. There is, therefore, evidence that PMSG may cause vaginal oestrus in some chinchilla (see also Text-fig. 1) but, in the conditions tested, it does not cause ovulation; coitus or HCG administration after PMSG treatment appears to be necessary.

HCG alone. Doses of 10,25 and 50 i.u. HCG were injected intraperitoneally 
into six, three and three chinchilla, respectively, which were killed 2 to 8 days later. Two animals in each of the last two groups were unilaterally ovariectomized just before treatment so that the removed ovary could be considered as a

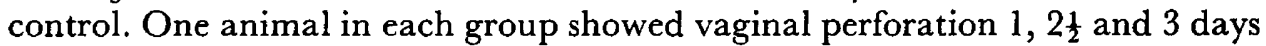
after treatment, and in two of these animals, one treated with 50 i.u. HCG and the other with 25 i.u., the remaining ovary contained new corpora lutea. There was no evidence in the resected ovaries of these two animals that a spontaneous ovulation was imminent.

In the two groups given the higher doses, the ovaries appeared to be overstimulated and follicles and interstitial tissue were luteinizing. These effects were not apparent at the 10-i.u. dose level and, therefore, this dose was not exceeded in subsequent treatments.

\section{DISCUSSION}

The direct action on the ovary of the gonadotrophins used in this study is to stimulate the growth of follicles, leading to their rupture and the formation of corpora lutea. The rationale of the treatment is, therefore, the induction of an ovarian cycle, the normality of which may be gauged by the capacity of the sex hormones produced in this cycle to cause perforation of the vaginal closure membrane which is indicative of oestrus. The latter event may be assessed by the willingness of the animals to mate and their ability to conceive. Since the purpose of the present experiments was to discover a method of inducing fertility in the chinchilla, the criterion of success must include the ability of the treatment to induce ovulation and coincident oestrus.

Throughout the series, the ovaries appeared more normal than many of those in the previous experiments in that luteinization was confined to the ovulated follicles. The normality is also borne out by the mean number of eggs ovulated per animal; the apparent drop is due to fewer animals producing a number of eggs which is in excess of the usual number ovulated (2.5). Most of the treated animals ovulated one to four eggs and only seven ovulated six or more ova. Four of these were duplicates of regimens II and IV of the previous series and another two were both 4-day treatments. In those chinchilla that may be regarded as having superovulated, the hormonal conditions were obviously awry because the ovaries appeared excessively luteinized and egg-recovery rates from the Fallopian tube were low. An ovulation number of one to three per ovary (Weir, 1967b) is indicative of a normal ovarian response. The ovulation rate in the present series as a whole ( 2.6 per animal) would seem appropriate for the production of an average of two young per litter. Most commercial breeders do not favour large litters because of the risk of difficulties arising during lactation.

It is noteworthy that in this species, unlike the rat (Rowlands, 1944), mouse (Wilson \& Zarrow, 1962) and rabbit (Kennelly \& Foote, 1965), there is no clear relationship between the size of dose or the duration of treatment of either PMSG or HCG and the response produced. Individual variation in the ovulatory response to HCG was much less in chinchilla in which the priming dose of PMSG extended over 5 days compared with those animals injected for 3 days. 
This suggests that the 6-day treatment represents a closer approximation to the normal rate of follicular growth. The chinchilla response may be affected by the amount of interstitial tissue in the ovary. This tissue may produce progestins (Hilliard, Archibald \& Sawyer, 1963) or androgens or oestrogens (Falck, Menander \& Nordanstedt, 1962) that could aid the induction of behavioural oestrus.

Of the animals showing vaginal oestrus, $25 \%$ mated and $64 \%$ of these became pregnant. A further three animals became pregnant after artificial insemination. Eight pregnancies were allowed to go to term and the offspring produced were completely normal. Only one instance of early embryonic resorption was found, but this is not uncommon in chinchilla and the hormonal environment in these experimental chinchilla can be regarded as having been adequate for the conception and maintenance of pregnancy.

Table 2. The relationship between vaginal perforation and ovulation in sixty-seven chinchilla treated with exogenous gonadotrophins (see Table 1)

\begin{tabular}{l|c|c}
\hline & Ovulation & No ovulation \\
\cline { 1 - 2 } Vagina perforate & 46 & 4 \\
Vagina not perforate & 9 & 8 \\
Total & 55 & 12 \\
\hline
\end{tabular}

Ten treated chinchilla (not included in the above analyses) were found at autopsy to have been injected inadvertently with PMSG and HCG in early pregnancy (Days 7 to 64). Only one of these ovulated, and in this respect the species differs from the guinea-pig in which ovulation is more readily induced during pregnancy than at other times (Rowlands, 1956). The pregnancies in these ten chinchilla did not seem to have been affected in any way by the treatments given.

In comparison with the 1969 series, the present results indicate a fall of nearly $50 \%$ in the numbers of chinchilla ovulating. But the figure given in Table 1 represents only those chinchilla in which ovulation could be detected at autopsy or retrospectively from pregnancies. Moreover, animals that did not respond with vaginal oestrus were killed in preference to those that did in order to investigate the possible reasons for the failure. Although about half of these were found to have ovulated (Table 2), it can be seen that the majority of chinchilla that ovulated also came into oestrus at the same time. Of the sixty-seven animals in which it was possible to check the occurrence of ovulation, $82 \%$ had, in fact, ovulated and this corresponds well with the response in the earlier series.

Coitus appears to be effective in inducing ovulation should it occur before the HCG is given, reinforcing current opinion (Conaway, 1971) that there is a continuum between induced and spontaneous ovulators and that some of the latter may ovulate in response to coitus if this stimulus precedes the ovulatory surge of LH.

The chinchilla received from the commercial farmers are not necessarily 
good breeders; indeed, many animals are sent because they have not bred under ranch conditions. None of these chinchilla has been found to have any physical abnormalities or infections of the genital tract and their 'sterility' appears to be psychological in refusing to accept a male or because of reduced output of endogenous gonadotrophin. The measure of success reported here in overcoming these factors by exogenous gonadotrophins is encouraging and, with further refinements, could be of great benefit to the chinchilla industry. The technique has already proved valuable in the laboratory for increasing the chances of chinchilla becoming pregnant at all times of the year and such chinchilla have provided material for biochemical (Tam, 1971) and embryological (Roberts, 1971) studies.

\section{AGKNOWLEDGMENTS}

My thanks are given to Dr I. W. Rowlands for his encouragement and interest and to all the chinchilla breeders who generously gave their animals for this research. The work was supported by the Ford Foundation.

\section{REFERENGES}

Conaway, C. J. (1971) Ecological adaptation and mammalian reproduction. Biol. Reprod. 4, 239.

FAlck, B., Menander, D. \& Nordanstedt, O. (1962) Androgen secretion by the rat ovary. Nature, Lond. 193, 593.

Hilliard, J., Archibald, D. \& Sawyer, C. H. (1963) Gonadotropic activation of preovulatory synthesis and release of progestin in the rabbit. Endocrinology, 72, 59.

Kennelly, J. J. \& Foote, R. H. (1965) Superovulatory response of prepubertal and postpubertal rabbits to commercially available gonadotrophins. 7. Reprod. Fert. 9, 177.

RoBerts, C. M. (1971) The early development of some hystricomorph rodents with particular reference to Chinchilla laniger. 7. Reprod. Fert. 27, 488.

Rowlands, I. W. (1944) The production of ovulation in the immature rat. F. Endocr. 3, 384.

Rowlands, I. W. (1956) The corpus luteum of the guinea-pig. Ciba Fdn. Colloq. Ageing, 2, 69.

TAM, W. H. (1971) The production of hormonal steroids by ovarian tissues of the chinchilla (Chinchilla laniger). J. Endocr. 50, 267.

WEIR, B. J. (1966) Aspects of reproduction in chinchilla. 7. Reprod. Fert. 12, 410.

WEIR, B. J. (1967a) The care and management of laboratory hystricomorph rodents. Lab. Anim. 1, 95.

WEIR, B. J. (1967b) Aspects of reproduction in some hystricomorph rodents. Ph.D. thesis, University of Cambridge.

WeIR, B. J. (1969) The induction of ovulation in the chinchilla. F. Endocr. 43, 55.

WEIR, B. J. (1970) Chinchilla. In: Reproduction and Breeding Techniques for Laboratory Animals, chap. 11, p. 209. Ed. E. S. E. Hafez. Lea \& Febiger, Philadelphia.

Wilson, E. D. \& Z ARRow, M. X. (1962) Comparison of superovulation in the immature mouse and rat J. Reprod. Fert. 3, 148. 